\title{
Circulating serotonin levels in COPD patients: a pilot study
}

Pietro Pirina ${ }^{1,2^{*}} \mathbb{D}$, Elisabetta Zinellu', Panagiotis Paliogiannis ${ }^{3}$, Alessandro G. Fois ${ }^{2}$, Viviana Marras ${ }^{2}$, Salvatore Sotgia ${ }^{3}$, Ciriaco Carru ${ }^{3}$ and Angelo Zinellu ${ }^{3}$

\begin{abstract}
Background: Chronic obstructive pulmonary disease (COPD) is a major and increasing global health problem. Serotonin is a neurotransmitter that participates in several pulmonary functions and it has been involved in oxidative stress, which plays essential roles in the pathogenesis of COPD. The current study aimed at establishing the levels of circulating serotonin in COPD, and investigating eventual relations between serotonin and oxidative stress markers.

Methods: Whole blood serotonin was assessed in 43 consecutive patients with stable COPD and in 43 age and sex-matched healthy controls.

Results: Serotonin blood levels were significantly higher in COPD patients than in controls (median $0.81 \mu \mathrm{mol} / \mathrm{L}$, IQR: $0.61-4.02$ vs $0.65 \mu \mathrm{mol} / \mathrm{L}, \mathrm{IQR}: 0.53-1.39, p=0.02)$. The univariate logistic regression analysis evidenced that serotonin levels are independently associated with presence of COPD (crude $\mathrm{OR}=7.29,95 \% \mathrm{Cl}: 1.296-41.05, p=0.003)$ and such an association was confirmed also after adjusting for several confounders (OR 21.92, 95\% Cl 2.02-237.83; $p=0.011$ ).
\end{abstract}

Conclusions: Our study showed higher levels of circulating serotonin in COPD and an inverse correlation with the worsening of airway obstruction. Future studies are necessary to investigate the clinical utility of this finding.

Keywords: COPD, Oxidative stress, Serotonin, Markers

\section{Background}

COPD is an increasing global health problem that nowadays represents the third leading cause of death in the world $[1,2]$. It is a chronic progressive disease characterized by a not fully reversible airflow limitation, associated with a chronic inflammation of the lungs and small airways [3, 4]. Although cigarette smoking represents the most known risk factor, in-door and out-door pollution, second-hand smoking and genetic conditions, such as $\alpha_{1}$ antitrypsin deficiency, are considered important additional risk factors [5-7]. The noxious compounds present in cigarette smoke and in environmental pollution, trigger the inflammatory response of the airways and the lungs in susceptible subjects,

\footnotetext{
*Correspondence: pirina@uniss.it

'Department of Respiratory Diseases, University Hospital Sassari (AOU), Sassari, Italy

${ }^{2}$ Department of Clinical and Experimental Medicine, University of Sassari, Sassari, Italy

Full list of author information is available at the end of the article
}

causing epithelial injury with subsequent production of reactive oxygen species (ROS) $[8,9]$. The increased amount of oxidants together with the depletion of antioxidant defenses, results in oxidative stress. It is now recognized that oxidative stress is involved in the pathogenesis of COPD $[9,10]$ and, in this regard, several biomarkers have been evaluated [11].

Serotonin (5-hydroxytyptamine, 5-HT) is a ubiquitous neurotransmitter that plays important roles in pulmonary functions, being involved in the modulation of respiratory rhythm and in pulmonary vasoconstriction [12, 13]. Furthermore, serotonin has been implicated in the pathogenesis of some of the main comorbidities of COPD, like depression [14, 15] despite the relation between serotonin, COPD and depression is still to be verified.

Moreover, serotonin has been reported to induce oxidative stress via monoamine oxidase-dependent pathway in human heart valves [16] and in mesenchymal 
stem cells [17] indicating that serotonin metabolism may be involved in oxidative stress. Its role in the genesis and maintenance of oxidative stress in COPD patients is not well-established. In this pilot study we focused on the assessment of blood serotonin levels in COPD patients compared to healthy controls and in relation to airway obstruction severity; we have also evaluated potential associations between serotonin and oxidative stress markers, like thiobarbituric acid reactive substances (TBARS) and protein sulfhydryl groups (PSH), which have been demonstrated in previous studies to be altered in patients with COPD $[18,19]$.

\section{Methods}

\section{Subjects}

This case-control pilot study involved 43 consecutive patients with stable COPD (mean age $74.8 \pm 5.9$ years, range 52-85 years), treated at the Respiratory Unit of the University of Sassari.

The diagnosis of COPD was made in accordance with the Global Initiative for Chronic Obstructive Lung Disease criteria [20]. The patients enrolled did not have a previous diagnosis of COPD and they were not under treatment with long- or short-acting $\beta$-agonists, or long-acting muscarinic antagonists, as well as with inhaled corticosteroids at least within 4 weeks prior to enrollment. Each patient performed respiratory function tests and underwent physical examination, blood tests and chest radiographs. The functional diagnosis of COPD was based on the presence of not fully reversible airflow limitation, defined by a post-bronchodilator ratio of forced expiratory volume in $1 \mathrm{~s}$ to forced vital capacity (FEV1/FVC) $<70 \%$ of the predicted value [4]. In order to collect demographic and clinical data, including smoking history and information about occupational and/or in-door and out-door pollutants exposure, a structured questionnaire was administered. In particular, patients who were never smokers, had been exposed to other COPD risk factors: half of them were women exposed to second-hand smoke, three of them had worked as miners and therefore exposed to silica powders and two of them had been exposed to indoor pollutants (biomass heating, etc).

A group of 43 age- and sex-matched healthy controls, with no medical history, was also included. Subjects with severe concomitant diseases, such as heart diseases, kidney and liver diseases, systemic inflammatory diseases, patients with severe COPD and patients with a history of asthma and atopic diseases, were excluded from the study. The study was approved by the Institutional Local Ethics Committee (Azienda Sanitaria Locale $\mathrm{n}^{\circ} 1$ di Sassari (Italy) (prot. 2175/CE del 21/04/2015). The subjects who decided to participate, signed a written informed consent before enrollment.

\section{Biochemical analysis}

The levels of serotonin in whole blood of COPD subjects and healthy controls were determined according to a method previously described [21]. The inter-assay $\mathrm{CV}$ was $<8 \%$. The oxidative stress indices TBARS and PSH were measured as previously reported [22, 23]. TBARS assay was employed to measure malondialdehyde (MDA) and other aldehydes produced by lipid peroxidation induced by reactive oxygen species. TBARS were determined by measuring the absorbance at $535 \mathrm{~nm}$ after reaction with thiobarbituric acid. A calibration curve was obtained using MDA as reference standard. Plasma PSH determination was performed by spectrophotometry with $5,5^{\prime}$-dithiobis-2-nitrobenzoic acid (DTNB) as titrating agent by measuring the absorbance of conjugate at $405 \mathrm{~nm}$. Concentration in samples was determined from a GSH standard curve. ROS can oxidize protein $\mathrm{SH}$ to disulfide or sulfenic acid, leading to a reduction in $-\mathrm{SH}$ groups.

\section{Statistical analysis}

The results are expressed as mean (mean $\pm \mathrm{SD}$ ) or median values (median and IQR). The distribution of variables was evaluated by means of Shapiro-Wilk test. The statistical comparisons between groups were assessed by means of unpaired Student's t-test or Mann-Whitney rank sum test, as appropriate. Correlations between variables were estimated using Spearman's or Pearson's correlation, as appropriate. In order to verify the presence of association between variables potentially implicated in disease development, logistic regression analysis was performed. Receiver operating characteristics (ROC) curve analysis was used to test the ability of serotonin to predict COPD, alone and in combination with TBARS and PSH. ROC curves were obtained with calculation of the area under the curve (AUC). Optimal cut-off maximizing sensitivity and specificity was selected according to the Youden Index.

Statistical analyses were performed using MedCalc for Windows, version 15.4 64 bit (MedCalc Software, Ostend, Belgium) and SPSS for Windows, version 14.0 32 bit (IBM Corporation; Armonk, NY, USA).

\section{Results}

Table 1 reports the demographic and clinical characteristics in controls and COPD patients. As expected, COPD patients showed a reduced $F E V_{1}$ and $F E V_{1} / F V C$ ratio. There were no between-group differences in smoking status or BMI. Serotonin blood levels were significantly higher in COPD patients (median $0.81 \mu \mathrm{mol} / \mathrm{L}$, IQR: 0.61-4.02) than in controls (median $0.65 \mu \mathrm{mol} / \mathrm{L}$, IQR: $0.53-1.39$ ), $p=0.02$ (Fig. 1). As previously reported TBARS concentrations significantly increased, and PSH 
Table 1 Clinical and functional parameters of healthy subjects and COPD patients

\begin{tabular}{lll}
\hline & $\begin{array}{l}\text { Controls } \\
(n=43)\end{array}$ & $\begin{array}{l}\text { COPD } \\
(n=43)\end{array}$ \\
\hline Age (years) & $73 \pm 7$ & $75 \pm 6$ \\
Gender (F/M) & $9 / 34$ & $9 / 34$ \\
BMl $\left(\mathrm{kg} / \mathrm{m}^{2}\right)$ & $26 \pm 4$ & $27 \pm 4$ \\
Never smoked & $14(33 \%)$ & $10(23 \%)$ \\
Current smokers & $3(7 \%)$ & $3(7 \%)$ \\
Ex smokers & $26(60)$ & $30(70 \%)$ \\
FEV1 (L) & $2.8 \pm 0.6$ & $2.0 \pm 0.6^{* *}$ \\
FEV1 (\% predicted) & $112 \pm 14$ & $80 \pm 18^{* *}$ \\
FVC (L) & $3.4 \pm 0.7$ & $2.9 \pm 0.8^{*}$ \\
FVC (\% predicted) & $108 \pm 15$ & $88 \pm 15^{* *}$ \\
FEV1/FVC & $80.4 \pm 3.9$ & $66.6 \pm 4.8^{* *}$ \\
RV (L) & $2.0 \pm 0.5$ & $3.4 \pm 0.9^{* *}$ \\
RV (\% predicted) & $105 \pm 12$ & $137 \pm 32^{* *}$ \\
TLC (L) & $6.0 \pm 1.1$ & $6.4 \pm 1.1$ \\
TLC (\% predicted) & $107 \pm 10$ & $108 \pm 14$ \\
RV/TLC (\%) & $32 \pm 3$ & $53 \pm 9^{* *}$ \\
\hline
\end{tabular}

FEV1 Forced Expiratory Volume in the 1st second, FVC Forced Vital Capacity, FEV1/FVC Tiffeneau index (calculated as LLN)

${ }^{*} p<0.01,{ }^{* *} p<0.001$ obtained by Student's t-test

concentrations significantly decreased, according to COPD presence [18]. However, no significant correlations were observed between serotonin blood levels and oxidative stress indices. As reported in Fig. 2, Spearman's correlations in the whole study population indicated that serotonin blood values are inversely associated with $\mathrm{FEV}_{1}$ (rho $=-0.25, p=0.023$ ) and FVC (rho $=-0.26, p=0.017$ ). Table 2 summarizes the results of the univariate logistic regression analysis, which evidenced that serotonin levels were independently associated with presence of COPD (crude OR = 7.29, 95\% CI: 1.296-41.05, $p=0.003)$. This association remained significant also after adjusting for age, gender, BMI, smoking status, and oxidative stress indices (OR 21.92, 95\% CI 2.02-237.83; $p=0.011$ ).

ROC curve analysis was performed to evaluate the sensitivity, specificity, and diagnostic accuracy of serum serotonin levels alone, or in combination with $\mathrm{PSH}$ and TBARS, in distinguishing COPD from healthy subjects (Fig. 3 and Table 3). Serotonin alone, with a cut-off of $0.78 \mu \mathrm{mol} / \mathrm{L}$ discriminated COPD from controls with $53.5 \%$ sensitivity and $74.4 \%$ specificity (AUC $=0.647$, 95\% CI $0.537-0.747, p=0.014)$. Serotonin in combination with PSH and TBARS produced the best result, with an AUC of 0.830 (95\% CI 0.733-0.902, $p<0.0001$ ), sensitivity $76.7 \%$ and specificity $74.4 \%$. Pairwise comparison of ROC curves indicated that the combination of serotonin, $\mathrm{PSH}$ and TBARS yield a significant increase in AUC $(+0.183, p=0.0035)$ compared to AUC obtained with serotonin alone.

\section{Discussion}

Serotonin is a biogenic amine known for its role as a neurotransmitter. It is synthesized from L-tryptophan within the central nervous system (CNS), where it is stored in the presynaptic neurons. Serotonin synthesis outside the CNS is limited to enterochromaffin cells, while platelets take up serotonin from plasma representing a further major storing site for serotonin [24]. The main metabolic pathway of serotonin is the

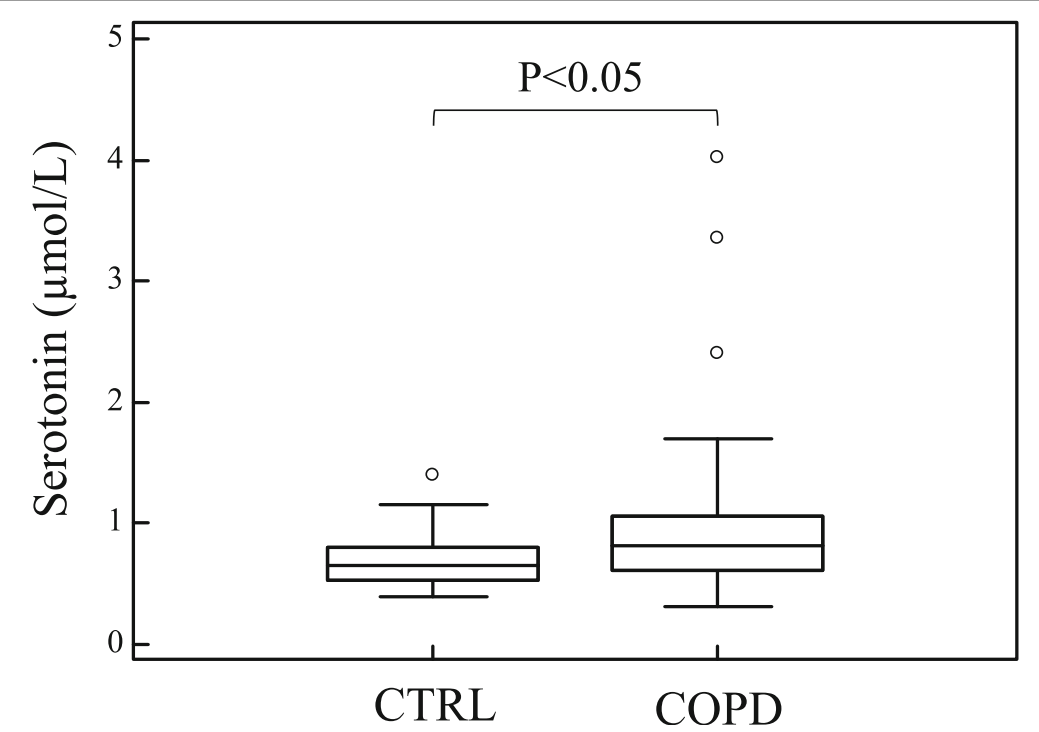

Fig. 1 Blood levels of serotonin in healthy subjects $(n=43)$ and in the totality of COPD patients $(n=43)$. The central horizontal line on each box represents the median, the ends of the boxes are 25 and 75 percentiles and the error bars 5 and $95 \%$. P-values derived from Student's t-test 

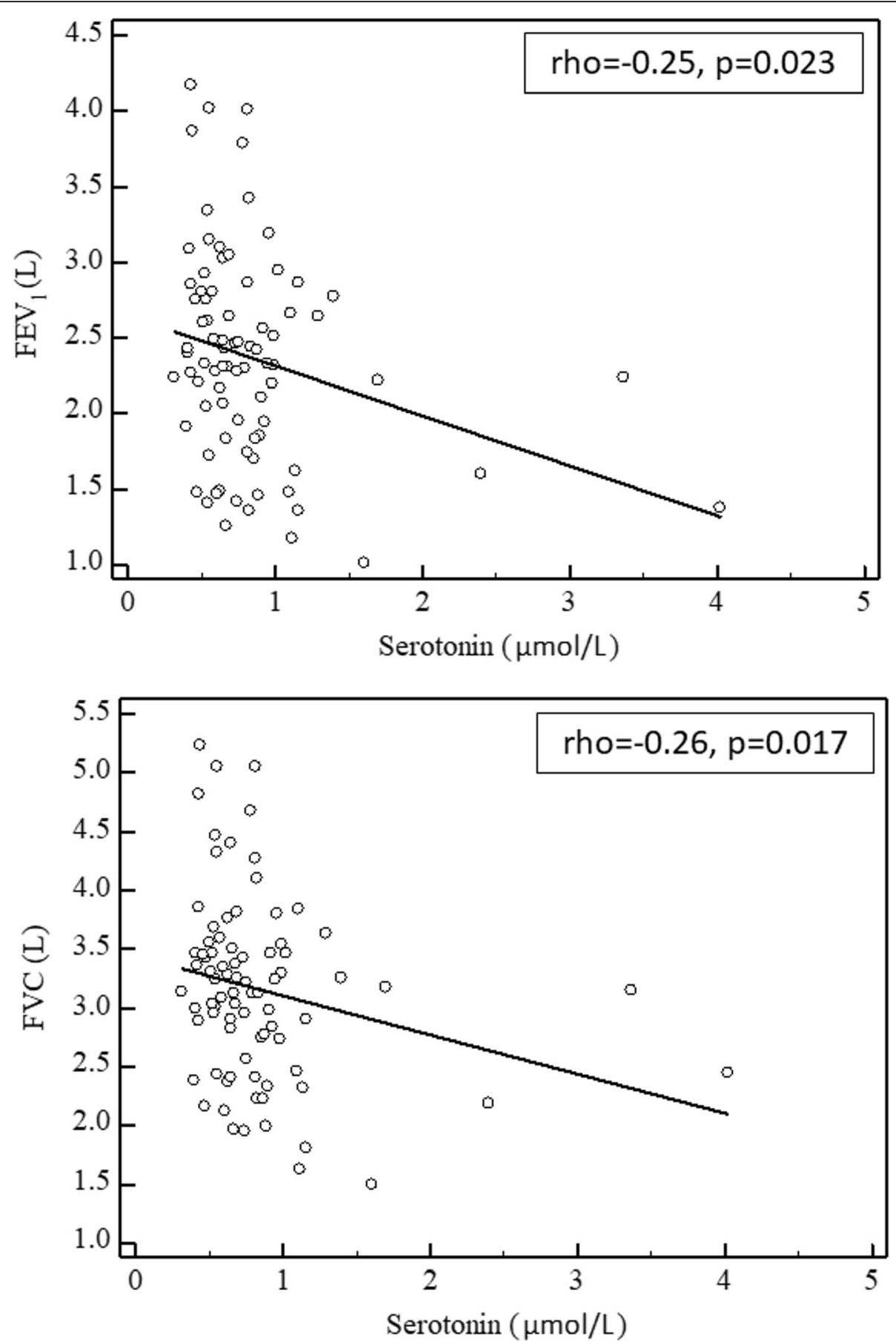

Fig. 2 Correlation between FEV1 and FVC with blood serotonin in COPD patients

metabolism by monoamine oxidase (MAO) that catalyses the oxidative deamination of the amine substrate, with production of its aldehyde intermediate and hydrogen peroxide as a by-product. The aldehyde intermediate is then rapidly oxidized by aldehyde dehydrogenase to 5-hydroxyindoleacetic acid [24, 25].

It is known that lung represent an important site in which removal and metabolism of serotonin take place [26]. The ability of the endothelial cells of the lungs to metabolise amines may be reduced in disease states, and this could explain their increased levels in the circulation. Elevated circulating levels of serotonin have been reported in respiratory diseases such as asthma [27] and lung cancer [28]. COPD has also been associated with a variation of a transporter gene involved in serotonin re-uptake [29] and metabolites 
Table 2 Predicting factors for chronic obstructive pulmonary disease

\begin{tabular}{|c|c|c|c|c|c|c|}
\hline \multirow[t]{2}{*}{ Factor } & \multicolumn{3}{|c|}{ Univariate analysis } & \multicolumn{3}{|c|}{ Multivariate analysis } \\
\hline & Crude OR & $95 \% \mathrm{Cl}$ & $p$-value & $\mathrm{OR}$ & $95 \% \mathrm{Cl}$ & $p$-value \\
\hline Age & 1.035 & $0.967-1.109$ & 0.749 & 0.998 & $0.917-1.088$ & 0.978 \\
\hline Gender & 1.000 & $0.368-2.720$ & 0.061 & 1.567 & $0.341-7.203$ & 0.563 \\
\hline BMI & 1.076 & $0.953-1.216$ & 0.692 & 1.108 & $0.942-1.303$ & 0.217 \\
\hline Smoking status & 1.404 & $0.551-3.581$ & 1.000 & 0.516 & $0.144-1.854$ & 0.319 \\
\hline PSH & 0.427 & $0.258-0.705$ & 0.0001 & 0.289 & $0.144-0.580$ & 0.0005 \\
\hline TBARS & 1.816 & $1.053-3.131$ & 0.02 & 2.947 & $1.322-6.570$ & 0.008 \\
\hline Serotonin & 7.294 & $1.296-41.05$ & 0.003 & 21.92 & $2.02-237.83$ & 0.011 \\
\hline
\end{tabular}

$B M I$ body mass index, $P S H$ protein sulfhydryl groups, TBARS thiobarbituric acid reactive substances, $O R$ odds ratio, $C l$ confidence interval

of the serotonin pathway have been associated with adverse outcome in exacerbated COPD [30]. Furthermore, it is now recognized that oxidative stress is involved in the pathogenesis of COPD [9, 10] and it has been reported that serotonin induces oxidative stress via MAO-dependent pathway in human heart valves [16] and in mesenchymal stem cells [17]. Moreover, it has been described that cigarette smoke, a major COPD risk factor, inhibit MAO in different species in vitro [31]. Such evidences suggest that serotonin may play relevant roles in the pathogenesis of COPD.
Our study has evidenced a significant increase in serotonin levels in COPD patients compared to controls. Spearman's correlations indicated that blood serotonin values are inversely associated with FEV1 and FVC, to confirm an association of serotonin levels not only with the presence of COPD, but also with the severity of airway obstruction. The univariate logistic regression analysis has shown that serotonin levels were independently associated with presence of COPD also after adjusting for age, gender, BMI, smoking status, and oxidative stress indices.

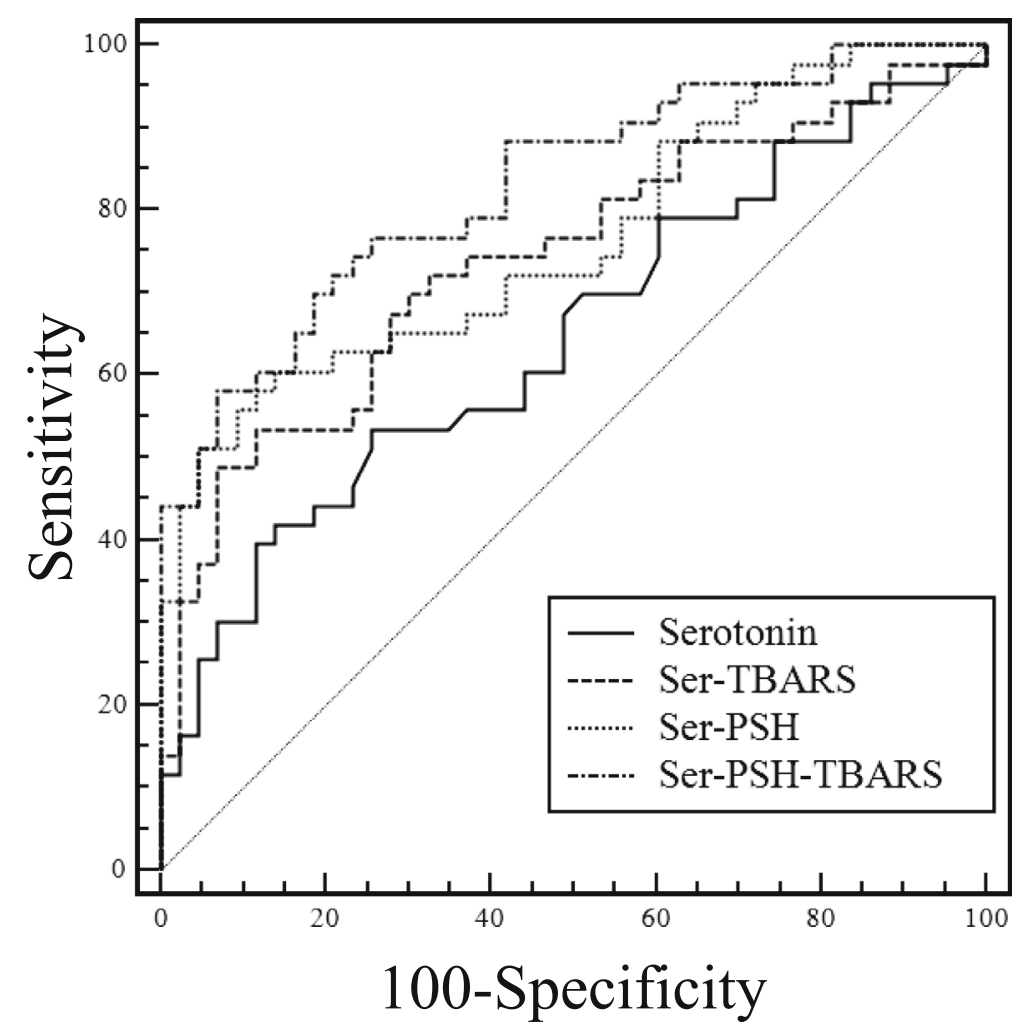

Fig. 3 The area under receiver operating characteristic curves of serotonin 
Table 3 Prognostic accuracy of serotonin alone or in combination with TBARS and MDA

\begin{tabular}{lllllll}
\hline Marker & AUC & $95 \% \mathrm{Cl}$ & $p$ value & Cut-off & Sensib & Specif \\
\hline Serotonin & 0.647 & $0.537-0.747$ & 0.014 & $>0.780$ & $53.5 \%$ & $74.4 \%$ \\
Ser-TBARS & 0.741 & $0.635-0.829$ & $<0.0001$ & $>0.543$ & $53.5 \%$ & $88.4 \%$ \\
Ser-PSH & 0.764 & $0.660-0.849$ & $<0.0001$ & $>0.569$ & $60.5 \%$ & $86.1 \%$ \\
Ser-PSH-TBARS & 0.830 & $0.733-0.902$ & $<0.0001$ & $>0.460$ & $76.7 \%$ & $74.4 \%$ \\
\hline
\end{tabular}

PSH protein sulfhydryl groups, TBARS thiobarbituric acid reactive substances, $M D A$ malondialdehyde, $A U C$ area under the curve, $\mathrm{Cl}$ confidence interval

Lau et al. [32], investigated the role of serotonin in the pathogenesis of COPD and found higher levels of circulating serotonin in patients compared to healthy controls. Unlike us, they examined only male COPD subjects who were significantly older than controls, and found a positive correlation between serotonin levels and age in pathological subjects. Moreover, in their analysis they prevalently included moderate to very severe COPD cases, finding no differences in serotonin levels according to disease progression. In our study, we confirmed the presence of higher blood serotonin levels in COPD compared to age- and sex-matched controls. As opposed to the study of Lau et al., our patients had a mild-moderate degree of airway obstruction (FEV1 $>50 \%$ ). From this point of view these patients can be considered in the early phase of the disease. In fact, they were all newly diagnosed patients who had not yet started a treatment. These data support the hypothesis that serotonin could be a predictive marker of the onset of COPD. Moreover, the inverse correlation that we found between serotonin levels and FEV1 and FVC, suggests a relation of this molecule with the worsening of airway obstruction.

The ROC curve analysis for serotonin significantly discriminate patients with COPD from those without COPD and showed that the diagnostic accuracy is higher when serotonin is combined with TBARS and PSH. In particular, the triple combination of serotonin, TBARS and PSH increased significantly the AUC of the ROC curve. Although it is an interesting result, its clinical validity and usefulness needs to be further investigated. Moreover, Spearman's correlation analysis failed to find a relationship between serotonin and oxidative stress biomarkers. This could be due to the low number of subjects involved, in particular to the absence of severe COPD subjects. The small number of cases, and the lack of advanced stage COPD patients represent the main limitations of our work. On the other hand, our study is the first to investigate blood serotonin levels in a cohort of early COPD cases and has several strengths, like its prospective case-match design, the accurate statistical analysis, and the research of associations with other well-established biomarkers of oxidative stress.

\section{Conclusions}

Our study confirms literature data showing an involvement of serotonin in the pathogenesis of COPD, demonstrating a statistically significant increase of circulating serotonin levels in an early phase of the disease, and a relation with the worsening of the airway obstruction. Given the need of biomarkers useful to detect and monitor COPD and its response to treatments, this seems to be a promising result that need to be further investigated.

\section{Abbreviations \\ 5-HT: Serotonin; AUC: Area under the curve; BMl: Body mass index; CNS: Central nervous system; COPD: Chronic obstructive pulmonary disease; FEV1: Forced expiratory volume in the 1st second; FVC: Forced vital capacity; MAO: Monoamine oxidase; MDA: Malondialdehyde; PSH: Protein sulfhydryl groups; ROC: Receiver operating characteristics; TBARS: Thiobarbituric acid reactive substances}

\section{Acknowledgements}

Not applicable.

Funding

This research did not receive any specific grant from funding agencies in the public, commercial, or not-for-profit sectors.

\section{Availability of data and materials}

The datasets generated and analysed during the current study are not publicly available.

\section{Authors' contributions}

PP1 participated in the design of the study and drafted the manuscript. EZ helped to draft the manuscript and contributed to the biochemical analysis. PP2 and AGF helped to draft the manuscript. VM and SS contributed to the biochemical analysis. CC contributed to the statistical analysis. AZ conceived and designed the study, was responsible for data extraction and performed statistical analysis. All authors have critically revised the manuscript and have approved the final version.

\section{Ethics approval and consent to participate}

The study was approved by the Institutional Local Ethics Committee (Azienda Sanitaria Locale $n^{\circ} 1$ di Sassari (Italy) (prot. 2175/CE del 21/04/2015), and was in accordance with the principles of Declaration of Helsinki. All subjects provided written informed consent.

\section{Consent for publication}

Not applicable.

\section{Competing interests}

The author Pietro Pirina is currently acting as an Associate Editor for BMC Pulmonary Medicine. All other authors declare that they have no competing interests.

\section{Publisher's Note}

Springer Nature remains neutral with regard to jurisdictional claims in published maps and institutional affiliations.

\section{Author details}

${ }^{1}$ Department of Respiratory Diseases, University Hospital Sassari (AOU), Sassari, Italy. ${ }^{2}$ Department of Clinical and Experimental Medicine, University of Sassari, Sassari, Italy. ${ }^{3}$ Department of Biomedical Sciences, University of Sassari, Sassari, Italy.

Received: 16 November 2017 Accepted: 25 October 2018 Published online: 08 November 2018

\section{References}

1. López-Campos JL, Tan W, Soriano JB. Global burden of COPD. Respirology. 2016;21(1):14-23. 
2. Lozano R, Naghavi M, Foreman K, Lim S, Shibuya K, Aboyans V, Abraham J, Adair T, Aggarwal R, Ahn SY, Alvarado M, Anderson HR, Anderson LM, Andrews KG, Atkinson C, et al. Global and regional mortality from 235 causes of death for 20 age groups in 1990 and 2010: a systematic analysis for the Global Burden of Disease Study 2010. Lancet. 2012;380(9859):2095-128.

3. Decramer M, Janssens W, Miravitlles M. Chronic obstructive pulmonary disease. Lancet. 2012;379:1341-51.

4. Vogelmeier CF, Criner GJ, Martinez FJ, Anzueto A, Barnes PJ, Bourbeau J, Celli BR, Chen R, Decramer M, Fabbri LM, Frith P, Halpin DM, López Varela MV, Nishimura M, Roche N, Rodriguez-Roisin R, Sin DD, Singh D, Stockley R, Vestbo J, Wedzicha JA, Agusti A. Global Strategy for the Diagnosis, Management, and Prevention of Chronic Obstructive Lung Disease 2017 Report: GOLD Executive Summary. Eur Respir J. 2017;49(3). https://doi.org/ 10.1183/13993003.00214-2017.

5. Mannino DM, Buist AS. Global burden of COPD: risk factors, prevalence, and future trends. Lancet. 2007;370:765-73.

6. Eisner MD, Anthonisen N, Coultas D, Kuenzli N, Perez-Padilla R, Postma D, Romieu I, Silverman EK, Balmes JR, Committee on Nonsmoking COPD, Environmental and Occupational Health Assembly. An official American Thoracic Society public policy statement: novel risk factors and the global burden of chronic obstructive pulmonary disease. Am J Respir Crit Care Med. 2010;182:693-718.

7. Gooptu B, Ekeowa UI, Lomas DA. Mechanisms of emphysema in alpha1antitrypsin deficiency: molecular and cellular insights. Eur Respir J. 2009;34:475-88.

8. Larsson K. Aspects on pathophysiological mechanisms in COPD. J Intern Med. 2007;262(3):311-40

9. Kirkham PA, Barnes PJ. Oxidative stress in COPD. Chest. 2013;144(1):266-73.

10. Santus P, Corsico A, Solidoro P, Braido F, Di Marco F, Scichilone N. Oxidative stress and respiratory system: pharmacological and clinical reappraisal of N-acetylcysteine. COPD. 2014;11(6):705-17.

11. Zinellu E, Zinellu A, Fois AG, Carru C, Pirina P. Circulating biomarkers of oxidative stress in chronic obstructive pulmonary disease: a systematic review. Respir Res. 2016;17(1):150

12. Hilaire G, Voituron N, Menuet C, Ichiyama RM, Subramanian $\mathrm{HH}_{\text {, }}$ Dutschmann $M$. The role of serotonin in respiratory function and dysfunction. Respir Physiol Neurobiol. 2010;174(1-2):76-88.

13. Morecroft I, Loughlin L, Nilsen M, Colston J, Dempsie Y, Sheward J, Harmar A, MacLean MR. Functional interactions between 5-hydroxytryptamine receptors and the serotonin transporter in pulmonary arteries. J Pharmacol Exp Ther. 2005:313(2):539-48.

14. Blier $P, E l$ Mansari M. Serotonin and beyond: therapeutics for major depression. Philos Trans R Soc Lond Ser B Biol Sci. 2013;368(1615):20120536.

15. Yohannes AM, Alexopoulos GS. Depression and anxiety in patients with COPD. Eur Respir Rev. 2014;23(133):345-9.

16. Peña-Silva RA, Miller JD, Chu Y, Heistad DD. Serotonin produces monoamine oxidase-dependent oxidative stress in human heart valves. Am J Physiol Heart Circ Physiol. 2009;297(4):H1354-60.

17. Trouche E, Mias C, Seguelas MH, Ordener C, Cussac D, Parini A. Characterization of monoamine oxidases in mesenchymal stem cells: role in hydrogen peroxide generation and serotonin-dependent apoptosis. Stem Cells Dev. 2010;19(10):1571-8.

18. Zinellu A, Fois AG, Sotgia S, Sotgiu E, Zinellu E, Bifulco F, Mangoni AA, Pirina P, Carru C. Arginines plasma concentration and oxidative stress in mild to moderate COPD. PLoS One. 2016;11(8):e0160237.

19. Zinellu A, Fois AG, Sotgia S, Zinellu E, Bifulco F, Pintus G, Mangoni AA, Carru C, Pirina P. Plasma protein thiols: an early marker of oxidative stress in asthma and chronic obstructive pulmonary disease. Eur J Clin Investig. 2016; 46(2):181-8

20. Global Strategy for the Diagnosis, Management, and Prevention of Chronic Obstructive Lung Disease 2017 Report. GOLD Executive Summary. Am J Respir Crit Care Med. 2017;195(5):557-82.

21. Zinellu A, Sotgia S, Deiana L, Carru C. Reverse injection capillary electrophoresis UV detection for serotonin quantification in human whole blood. J Chromatogr B Anal Technol Biomed Life Sci. 2012;895-896:182-5.

22. Esterbauer $\mathrm{H}$, Cheeseman KH. Determination of aldehydic lipid peroxidation products: malonaldehyde and 4-hydroxynonenal. Methods Enzymol. 1990; 186:407-21.

23. Ellman GL. Tissue sulfhydryl groups. Arch Biochem Biophys. 1959:82(1):70-7.

24. Mohammad-Zadeh LF, Moses L, Gwaltney-Brant SM. Serotonin: a review. J Vet Pharmacol Ther. 2008:31(3):187-99.
25. Lewis A, Miller JH, Lea RA. Monoamine oxidase and tobacco dependence. Neurotoxicology. 2007;28(1):182-95.

26. Block ER, Stalcup SA. Metabolic functions of the lung. Of what clinical relevance? Chest. 1982:81(2):215-23.

27. Lechin F, van der Dijs B, Orozco B, Lechin M, Lechin AE. Increased levels of free serotonin in plasma of symptomatic asthmatic patients. Ann Allergy Asthma Immunol. 1996;77(3):245-53.

28. Takahashi C, Goto E, Taira S, Kataoka N, Nishihara M, Katsumata T, Goto I, Takiuchi H. Serotonin syndrome in a patient with small cell lung cancer. Gan To Kagaku Ryoho. 2013;40(8):1059-61.

29. Ishii T, Wakabayashi R, Kurosaki H, Gemma A, Kida K. Association of serotonin transporter gene variation with smoking, chronic obstructive pulmonary disease, and its depressive symptoms. J Hum Genet. 2011;56(1):41-6.

30. Meier MA, Ottiger M, Vögeli A, Steuer C, Bernasconi L, Thomann R, ChristCrain M, Henzen C, Hoess C, Zimmerli W, Huber A, Mueller B, Schuetz P. Activation of the serotonin pathway is associated with poor outcome in COPD exacerbation: results of a long-term cohort study. Lung. 2017;195(3): $303-11$

31. Khalil AA, Davies B, Castagnoli N Jr. Isolation and characterization of a monoamine oxidase B selective inhibitor from tobacco smoke. Bioorg Med Chem. 2006;14:3392-8.

32. Lau WK, Chan-Yeung MM, Yip BH, Cheung AH, Ip MS, Mak JC, COPD Study Group of the Hong Kong Thoracic Society. The role of circulating serotonin in the development of chronic obstructive pulmonary disease. PLoS One. 2012;7(2):e31617.

\section{Ready to submit your research? Choose BMC and benefit from:}

- fast, convenient online submission

- thorough peer review by experienced researchers in your field

- rapid publication on acceptance

- support for research data, including large and complex data types

- gold Open Access which fosters wider collaboration and increased citations

- maximum visibility for your research: over $100 \mathrm{M}$ website views per year

At $\mathrm{BMC}$, research is always in progress.

Learn more biomedcentral.com/submissions 